Article

\title{
House Prices in the Peripheries of Mass Rapid Transit Stations Using the Contingent Valuation Method
}

\author{
Kuo-Cheng Hsu
}

Department of Urban Planning and Development Management, Chinese Culture University, NO.55, Hwa-Kang Road, Taipei 11114, Taiwan; kcurban@gmail.com; Tel.: +886-2-2861-0511 (ext. 41124)

Received: 17 September 2020; Accepted: 16 October 2020; Published: 20 October 2020

\begin{abstract}
With the implementation of growth management planning in urban areas and the realization of sustainable development visions, transit-oriented development has become a form of mainstream urban development. Relevant studies have verified that the market prices of houses in the peripheries of public transit stations are higher than those of regular houses. However, when buying a house, people make price decisions on the basis of their levels of identification with the amenities and environmental qualities of residential locations. The question arises whether current housing price levels in the peripheries of public transit stations properly reflect or over-reflect this consideration. To clarify this, this study selected the peripheries of mass rapid transit (MRT) stations in the Taipei metropolitan area in Taiwan as the research area and designed a willingness-to-pay questionnaire for houses in the peripheries of MRT stations by using the contingent valuation method. Subsequently, a Tobit regression model was established to estimate the prices that people are willing to pay for such houses. The results revealed that after the respondents had considered the advantages and disadvantages of the amenities and environmental qualities of the peripheries of MRT stations, they were willing to pay higher prices for a house in those areas than for a regular house. For houses in the peripheries of elevated stations, the respondents were willing to pay approximately $7.89 \%$ more than the average market price of the entire administrative district per square meter. For houses in the peripheries of underground stations, the respondents were willing to pay approximately $5.9 \%$ more than the average market price of the entire administrative district per square meter. However, in the peripheries of both elevated and underground stations, the current market house prices are higher than the price levels the respondents were willing to pay. In the peripheries of elevated stations, the market house prices are $33.55 \%$ higher, and those in the peripheries of underground stations are $14.82 \%$ higher than what the respondents were willing to pay.
\end{abstract}

Keywords: growth management; sustainable development; transit-oriented development; housing price; contingent valuation method

\section{Introduction}

In the development of urban areas, the land demand from industrial development, commercial activities, and resident behaviors results in suburbanization. Furthermore, lack of control regarding development locations and the consideration of land use efficiency have resulted in landscape patterns with low density, fragmentation, and leapfrogging. This is the so-called urban sprawl phenomenon [1-7]. As experienced in Europe and North America, the negative impacts of sprawl in urban spaces far outweigh the benefits. Furthermore, urban sprawl violates the principle of sustainable development. Relevant studies have supported such discourse on the aspects of land use, environmental resource preservation, urban and rural development, transportation, and public sector finance [1,4,8-12]. Consequently, the planning concept of growth management emerged, which is a systematic strategy and proposed solution for targeting the effects of this development trend of 
urban areas. Planning departments in the public sector intend to help urban areas achieve sustainable development through growth management. After 2000, this planning concept evolved into smart growth with the introduction of elements of urban design and building design to strengthen the habitability and attractiveness of downtown areas. People's willingness to move back from suburbs to downtown areas is expected to increase, and urban centers are encouraged to adopt a land use pattern of compactness and mixed use [13]. With the emergence of smart growth, transit-oriented development (TOD) has become a form of mainstream urban development in modern times. TOD is the use of a land development pattern with high density and mixed residential and commercial use along the corridors and stations of public transit systems. This improves the lifestyle amenities of the surrounding areas as well as the convenience of public transit systems. The purpose of this development is to centralize the activities of work, residence, commerce, and recreation to the areas surrounding public transit stations in addition to reducing the improper consumption of land resources as well as air and noise pollution.

Further studies on the major price-related characteristics of housing markets in these areas have indicated that the convenience of transport and great amenities in the peripheries of mass transit stations have positive effects on house prices in the area [14-20]. Benjamin and Sirmans (1996), Workman and Brod (1997), and Dueker and Bianco (1999) have conducted research on the peripheries of subway stations in Washington D.C., New York, and Portland in the United States, respectively. Their results have all indicated that the unit price of houses is higher closer to stations [21-23]. Mulley and Tsai (2016) verified that the unit price of houses within $400 \mathrm{~m}$ of metro stations was higher than those of houses in other areas after the metro started operations in Sydney, Australia [24]. Debrezion and Rietveld (2006) measured the influence of Dutch rail transit on house prices, and their results revealed that because of the noise caused by the stations, houses within $250 \mathrm{~m}$ of the stations had a unit price 5\% lower than that of houses $500 \mathrm{~m}$ from the stations [16]. Deng and Nelson (2016) investigated the influence of the Beijing subway system on house prices in China and discovered that subway stations have positive effects on housing prices in the surrounding areas. The established characteristic price model demonstrated that the houses within $100 \mathrm{~m}$ of public transit stations are influenced the most [25]. In Taiwan, studies by Liou et al. (2016), Shyr et al. (2013), Chiang (2013), and Peng et al. (2009) have verified that the mass rapid transit (MRT) system has positive effects on the prices of surrounding houses [26-29].

TOD strategies aim to solve the predicament of development imbalance in urban areas and attain sustainable development of the environment. The results of market mechanisms indicate that because of the planning actions implemented by the government with all its available resources, the houses in the peripheries of mass transit stations are considered a special house type. Studies have verified that market prices of such a special house type are higher than those of regular house products. The price discrepancy mainly occurs because people enjoy the living environments built in accordance with this special type of land use and are willing to pay higher prices for houses in the peripheries of mass transit stations. However, under the market mechanism, whether factors such as market price gouging cause real market prices to exceed the prices that people are willing to pay to enjoy the living environment is unclear. If urban development policies and strategies proposed by the public sector lead to an increase in people's costs for purchasing houses under price gouging, the favorable intention of such governmental policies may be compromised.

Developmental sprawl has appeared in the overall spatial structure of the Taipei metropolitan area in Taiwan [30]. To reverse this urban land use pattern, which violates sustainable development, and solve the conventional land use problem of the inability of zoning controls to respond to the rapid changes in industrial development and commercial activities, governmental urban planning agencies have gradually introduced growth management into planning systems at different levels and are actively implementing TOD strategies. However, the developmental characteristics of the Taipei metropolitan area and US metropolises differ. In the United States, severe spatial sprawl has caused the middle class to move to live in suburban areas, minimizing the number of residences in downtown areas. Therefore, TOD strategies are introduced to reinforce downtown public transport 
accessibility. The adoption of mixed use in the peripheries of mass transit stations can attract people to reside in downtown areas [31-33]. Under the special spatial structure in Taiwan, the developable land area and ratio are small. Combined with the development context of mixed use and common dense residential communities, Taipei features compact city characteristics according to US standards [30]. Urban sprawl occurs in the Taipei metropolitan area mainly because of high housing prices in the downtown areas, loopholes in land change systems, and population migration to suburbs promoted by public construction projects led by the governmental sector. Despite the urban sprawl, housing in downtown areas remains highly attractive [7]. Therefore, the Taipei metropolitan area implements TOD to reduce dependency in private transport and further improve urban living conditions. The planning department of the Taipei metropolitan area has made adjustments in urban planning, urban design, and land use control and developed the systems of floor area incentives and transfer of development rights to strengthen the land use intensities and mixed-use levels in the peripheries of MRT stations. However, whether the different causes and purposes of metropolitan development characteristics and the introduction of TOD for planning result in different profiles of housing markets in the peripheries of mass transit stations in Taipei and US metropolises remains unclear.

Consequently, the peripheries of MRT stations in the Taipei metropolitan area in Taiwan were selected as the research area in this study. After people's perceived satisfaction with the amenities and environmental qualities of the peripheries of the stations was clarified, the prices they were willing to pay to buy houses in the areas were calculated. In addition, actual market transaction prices were compared with the prices people were willing to pay, and the differences between the two were analyzed. In accordance with the study's purpose, we conducted an empirical analysis based on the contingent valuation method (CVM) to design a willingness-to-pay (WTP) questionnaire to assess the prices people were willing to pay to buy houses in the peripheries of MRT stations. Subsequently, a Tobit regression model was established, and the additional prices people were willing to pay for houses in the areas surrounding MRT stations compared with those for regular houses were calculated. Thus, the interactions among the living environment, residents' feelings, and the housing market derived from the planning concept of growth management could be understood. In addition, a novel price evaluation framework could be provided for this special house type.

\section{Research Area}

This study selected the Taipei metropolitan area in Taiwan as the research area. The Taipei metropolitan area consists of Taipei City, New Taipei City, and Keelung City and has an area of 2457 $\mathrm{km}^{2}$ and a population of 7,048,851. It is the largest metropolitan area in Taiwan. The Taipei metropolitan area is a highly concentrated political, economic, and cultural metropolis with 42 administrative districts. In 1996, the MRT system started operation in the Taipei metropolitan area. Currently, it has six lines with a total operating length of $167.2 \mathrm{~km}$ and a total of 119 stations. Different forms of stations have different influences on the surrounding environment, including landscape views, crowds, congregation of commercial activities, available open space, and noise and vibration generated by the MRT system's operation. Thus, the house prices are influenced. Consequently, the target area in this empirical study included the peripheries of elevated and underground MRT stations. Thus, whether people's WTP additional house prices differs based on different station forms can be further clarified.

To fit the scope of the study, the zoning of the selected peripheries of stations mostly comprises residential districts. In addition, these peripheries have commercial facilities that residents require in their daily lives. Consequently, the surrounding areas of six MRT stations were selected as the research area through the digital land use zoning inquiry system of Taipei City Government and New Taipei City Government as well as Google Maps. They were the peripheral areas of Mingde, Qilian, Beitou, Wanlong, Dapinglin, and Xindian District Office Stations. Among them, the first three stations are elevated MRT stations, and the latter three are underground MRT stations. The details are shown in Figure 1. 


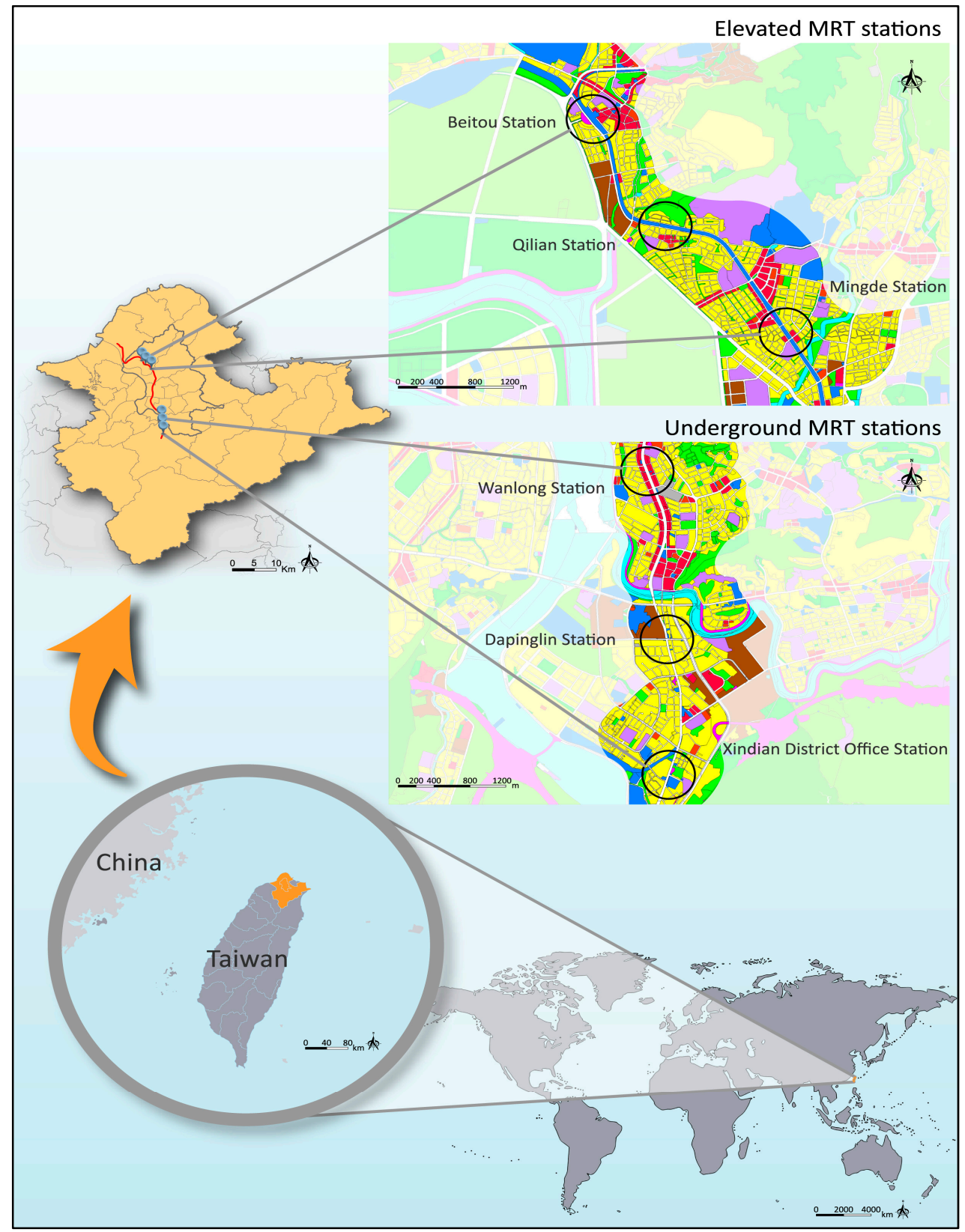

Figure 1. Locations of the study area (courtesy of Free Vector Maps).

\section{Study Design}

This study determined the value of houses in the areas surrounding stations as perceived by people by using objective evaluation models. Thus, two study hypotheses were proposed and verified. The first hypothesis is that because elevated and underground stations have different effects on their peripheries, the advantages and disadvantages of resulting amenities differ. Therefore, the prices people are willing to pay to purchase different types of houses in the peripheries of MRT stations differ. The second hypothesis was that although people are willing to pay higher prices to buy houses in the peripheries of MRT stations than they are to buy regular house products, the market prices of houses surrounding stations are higher than the prices people are willing to pay after considering the effects. Figure 2 presents the framework of the study design. After the empirical research area was determined, the system of factors influencing house prices in the peripheries of MRT stations was established. Subsequently, a questionnaire was designed on the basis of the CVM. Finally, a Tobit 
regression model of the areas surrounding elevated and underground stations was established. The additional prices that people are willing to pay for this special house type were estimated. The steps involved in each stage are presented in Figure 2.



Figure 2. Research procedure.

\subsection{Selection of Factors that Influence House Prices in the Peripheries of MRT Stations}

Factors influencing real estate prices include real estate characteristics, neighboring environments, and location [34]. Factors associated with location include distances to workplaces, schools, shopping districts, and public transit stations [35]. If houses are closer to public transit stations, including those for trains, buses, and subways, the commute cost will be reduced. Consequently, according to the compensation principle, people must spend relatively more to live in the peripheries of transit stations. In other words, real estate prices are closely related to the accessibility of public transit systems. Because convenient public transit systems provide people with greater transport convenience, the commute time cost is naturally transferred to the cost of buying or renting houses. In addition, houses near transit stations often have higher selling rates in the real estate market $[16,17]$. Belzer and Autler (2002) explored the housing markets in the peripheries of public transit stations in New York, Boston, Chicago, and San Francisco and concluded that such areas have high-quality amenities 
of abundant commerce and convenient transportation. Consequently, people prioritize such areas when selecting living locations, even if they must pay relatively higher rents and house prices [36]. Cervero and Duncan (2002) indicated that if an area within $400 \mathrm{~m}$ of a station has fine mixed land use pattern, the house prices in the surrounding areas will increase [20]. Bae et al. (2003) found that line 5 of the Seoul Metropolitan Subway in South Korea exerted a significant positive influence on the house prices of the surrounding areas even before it started operation. The reason was that people living in crowded urban environments with intensive development hope that public transit systems translate to superior transportation convenience and an enhanced living environment. Consequently, the value increase is reflected in advance in the housing market in the peripheries of the stations [19]. Lund (2006) explored the reasons that influence people living in the areas surrounding public transit stations in the three regions of the San Francisco Bay Area, Los Angeles, and San Diego and revealed family income to be a significant influencing factor [18]. Diaz and Mclean (1999) asserted that pedestrian-oriented street pattern designs are introduced more actively in areas surrounding public transit stations. As a result, the quality of life for residents in these areas improve, which becomes a factor positively influencing house prices. Conversely, noise pollution and privacy concerns negatively influence house prices [15]. Mulley et al. (2016) conducted research in Brisbane, Australia, and found that public transit stations exert positive influences (e.g., attracting the aggregation of commercial activities) and negative influences (e.g., causing noise and increasing crime rates near the stations) [14].

In sum, compared with regular house products, houses in the peripheries of public transit stations allow residents to enjoy more convenient transportation functions and abundant commercial functions. In addition, the aggregation of people and vehicles might exert negative impacts such as noise, unclean environments, and insufficient public security. Thus, the present study reviewed related literature and considered the development characteristics of the Taipei metropolitan area. The factors influencing house prices in the peripheries of MRT stations were determined from the three major dimensions of living environment convenience, resident health and safety, and living environment amenity. Thereafter, under the premise of people considering lifestyle amenities and environmental qualities, whether they are willing to pay more to buy houses in the peripheries of public transit stations was investigated. In addition, the amount that they would be willing to pay was estimated. A total of 13 influential factors under the 3 major dimensions were identified, as shown in Table 1 . Among them, six positive influenced house prices (GQ1 to GQ6) and seven had negative influences (BQ1 to BQ7).

Table 1. Factors influencing house prices in the peripheries of mass rapid transit (MRT) stations.

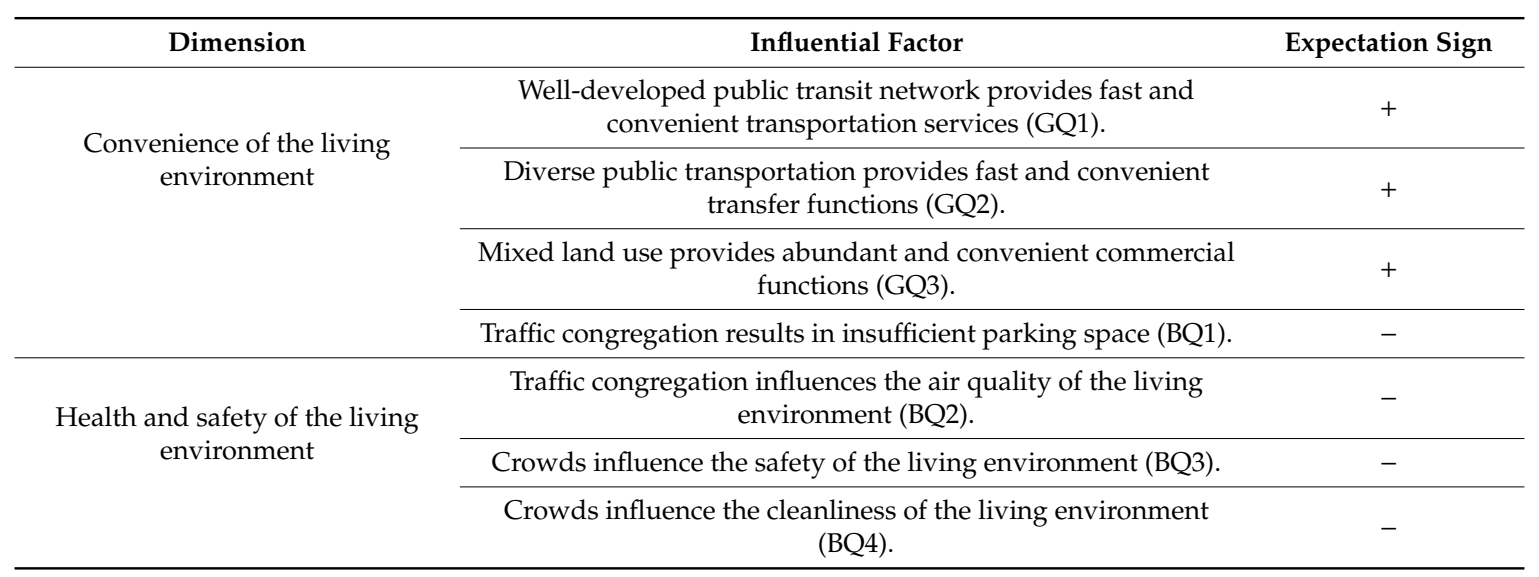


Table 1. Cont.

\begin{tabular}{|c|c|c|}
\hline Dimension & Influential Factor & Expectation Sign \\
\hline \multirow{6}{*}{ Amenity of the living environment } & $\begin{array}{l}\text { Additional open space at the stations improves the recreational } \\
\text { functions of the living environment (GQ4). }\end{array}$ & + \\
\hline & $\begin{array}{l}\text { Pedestrian walking systems around the stations improve the } \\
\text { convenience of the overall walking space (GQ5). }\end{array}$ & + \\
\hline & $\begin{array}{l}\text { Additional public art installations to the stations improve the } \\
\text { esthetics of the living environment (GQ6). }\end{array}$ & + \\
\hline & $\begin{array}{c}\text { Traffic congregation influences the serenity of the living } \\
\text { environment (BQ5). }\end{array}$ & - \\
\hline & $\begin{array}{l}\text { The noise and vibrations produced by the MRT systems } \\
\text { influence the serenity of the living environment (BQ6). }\end{array}$ & - \\
\hline & $\begin{array}{l}\text { The buildings and additional facilities of MRT stations influence } \\
\text { the landscapes of the living environment (BQ7). }\end{array}$ & - \\
\hline
\end{tabular}

\subsection{Utilization of the CVM}

The theoretical CVM was first proposed by Ciriacy-Wantrup in 1947 as a method for eliciting market valuation of a nonmarket good. The method was practically applied in 1963 by Davis to estimate the value hunters and tourists placed on a particular wilderness area [37]. The CVM is generally used in the estimation of the value of nonmarket goods. The principle of the CVM involves using various methods to elicit respondents' WTP for nonmarket goods. The CVM involves the following steps: establishing hypothetical markets, selecting survey methods (interviews, phone survey, and postal survey), selecting elicitation methods, estimating WTP, calibrating models, and inferring prices $[38,39]$. The CVM has been developed into a commonly used valuation method; however, some researchers have expressed concerns regarding its use, including respondents' hypothetical bias and testing for scope effects when respondents respond to a questionnaire. The reliability and validity of the final estimated WTP is also questionable. By contrast, some researchers have verified that the CVM is a reliable valuation method [40-45]. Mitchell and Carson (1989) and Hutchinson et al. (1995) indicated that with a rigor questionnaire structure, the CVM can be a trustworthy model to valuate nonmarket goods [46,47]. List (2001) claimed that hypothetical bias can be reduced by providing more information to respondents and encouraging them to imagine that they are actually engaged in a monetary transaction [48]. Fransico (2010) claimed that using an open double-bound dichotomous choice method to design questionnaires can increase their statistical validity [49].

The CVM can also be used for market goods for which prices are currently unavailable [50]. Mattia et al. (2013) indicated that conventional real estate can be appraised using the market comparative approach, cost approach, and capitalization approach. Appraisers determine real estate prices according to experience, values, data, and market conditions. However, the reliability of related data and information on the real estate market remains unclear in the appraisal process. Therefore, if the CVM can be used to determine the prices that people are willing to pay, the reliability of the appraised prices can be increased, and the influential factors as well as their influence levels on real estate prices in different submarkets or regional environments can be clearly understood [51]. Roddewig and Frey (2006) also believed that the CVM can be used to determine the real estate prices that buyers are willing to pay or the price levels that sellers are willing to accept [52].

In a related study, Mundy and Mclean (1998) studied the litigation case of American Smelting and Refining Company. The plaintiff claimed that the smelter exhaust gases contained arsenic, lead, and other heavy metals. Under the premise of impacts on the health of nearby residents and decreasing real estate values, the CVM was used to estimate that the house prices of the surrounding areas would decrease by $10-18 \%$ [53]. Simons and Throupe (2005) surveyed homeowners in South California through random sampling and used the CVM to demonstrate that the potential damage caused by toxic mold on house prices was as high as 60\% [54]. Simons and Geideman (2005) surveyed the influence of leaks in the underground oil storage equipment of gas stations on house prices in eight 
US states. The results indicated that the CVM can help analyze the reasons for reduced house prices from the residents' perspective [55]. Lipscomb et al. (2011) verified that the CVM has an effect on the appraisal of real estate value affected by pollution under circumstances in which market data are difficult to use as a reference or when market failure occurs. However, this valuation method has its advantages and limitations [56]. In addition, Kiel and McClain (1985), Chattopadhyay (2000), Beron et al. (2001), and Brasington and Hite (2005) targeted changes in the prices that people are willing to pay for houses if the air quality of the living environment improves [57-60]. Furthermore, Jim and Chen (2006) conducted questionnaire surveys on house buyers in Guangzhou City, China, and found that they were willing to pay more to purchase houses in communities with favorable living environmental qualities. For communities with green landscapes, house buyers were willing to pay an additional $7.1 \%$, whereas for communities with favorable and sufficient water sources, they were willing to pay an additional 13.2\% [61]. Another survey study on Klang, Malaysia, concluded that home buyers were willing to pay an additional $20.3 \%$ for houses within a commute time of $20 \mathrm{~min}$. If communities had adequate property management mechanisms and pleasant landscapes, they were willing to pay an additional 3.5\% [62].

Generally, methods that employ the CVM principle to explore WTP prices include the open-ended CVM, closed-ended CVM, sequential bids method, and payment card method. These methods are described as follows:

\subsubsection{Open-Ended CVM}

The first CVM to be used was the open-ended CVM proposed by Davis in 1963. In the open-ended CVM, respondents are directly asked the prices they are willing to pay under different circumstances without any related information or restrictions. This is considered the most direct price inquiry method because the respondents receive no hints. Consequently, respondents are allowed to reflect on the prices they have in mind with no restrictions. However, the major dispute regarding this method is that respondents do not have the basis for an overall understanding of the event, and the results are not objective. In addition, the prices proposed by respondents are often too high or too low. With no reasonable explanation, subsequent analysis and price valuation becomes difficult $[49,63]$.

\subsubsection{Closed-Ended CVM}

The closed-ended CVM can be further divided into the single-bounded dichotomous choice method and double-bounded dichotomous choice (DBDC) method. The single-bounded dichotomous choice method involves directly asking respondents whether they agree on a random price. Carson, Hanemann, and Mitchel further proposed the DBDC method in 1986. The statistical efficiency of the contingent evaluation is increased with the use of dichotomous choices because it involves two inquiry steps. Specifically, respondents are first allowed to understand the reason for the price inquiry before being asked whether they agree to a first offer. The second inquiry depends on the respondents' responses to the initial offer. If they are willing to pay for the first offer, then the second offer is set higher than the first. If they are unwilling to pay, then the second offer is set lower than the first [64].

\subsubsection{Sequential Bids Method}

The sequential bids method is similar to auction bidding, and its goal is to determine the final price that people are willing to pay. The inquirer first proposes an initial price. If the respondent does or does not accept the price, the price will be gradually increased or reduced until the respondent is unwilling to further negotiate the price. Although the method may be influenced by the starting point deviation, the respondents are allowed sufficient time for consideration in the inquiry process. To a certain level, this method has higher validity than the open-ended and closed-ended CVMs [63,65]. 


\subsubsection{Payment Card Method}

In this method, the inquirer provides a price list and asks respondents for the highest amount they are willing to pay. The method avoids using a single inquiry point. In contrast to the open-ended $\mathrm{CVM}$, this method allows respondents to understand the inquiry reason. Because the prices of the highest and lowest limits must be provided, the inquiry method can reduce the deviation problems arising from different starting prices [63,64].

The four aforementioned methods have advantages and disadvantages. The empirical results by Mattia et al. (2013) indicated that the DBDC method yields prices with smaller differences from actual market prices [51]. However, the DBDC method involves directly asking respondents whether they agree on a random price. Thus, the awareness and decision-making of respondents may be limited to that price. The deviations derived from this method influence the accuracy of the final estimated prices $[65,66]$. To solve this problem, the open DBDC method can be used, which combines the open-ended CVM and DBDC method. After two inquiries, the questionnaire allows respondents to freely fill out the prices they are willing to pay. Thus, the problems of limited WTP price intervals as well as limited willingness of respondents can be solved [49]. Consequently, this study adopted the open DBDC method of CVM. After two inquiries, respondents were guided to answer with the amount they were willing to pay. They only needed to answer if they were willing to pay a certain amount to buy the houses in the peripheries of MRT stations. Thus, the difficulty in answering was reduced, and the valuation results were reliable. In addition, to solve the problem of the initial prices proposed by respondents being too low, before designing the questionnaire, this study first conducted a pretest questionnaire survey. Subsequently, the model of the open-ended method was used to determine the price basis for the official questionnaire.

Empirical studies that adopt the CVM for elicitation mostly use a general continuous regression model for calibration. Although the calibration results can help determine the respondents' WTP, low explanatory power of the model is frequently obtained because WTP is a constrained continuous variable rather than a general continuous variable. Therefore, this study adopted a Tobit regression model with WTP as a constrained continuous variable within a given range. The use of the Tobit model for analysis can prevent measurement or sample errors caused by unobservable factors. The WTP function is expressed as follows:

$$
W T P_{i}=\beta_{0}+\beta_{1} \times X_{1}+\beta_{2} \times X_{2}+\beta_{3} \times X_{3}+\cdots+\beta_{n} \times X_{n}+\varepsilon_{i}
$$

where $W T P_{i}$ represents the WTP additional prices per square meter for houses in the peripheries of MRT stations; this variable is assumed to be continuous. $\beta_{0} \ldots \beta_{n}$ represent the calibration coefficients; $X_{1} \ldots X_{n}$ represent the independent variables affecting WTP; $\varepsilon_{i}$ presents the random error term; $n$ represents the number of independent variables; and $i$ represents the sample size. The WTP of individual respondents and average WTP are expressed in Equations (2) and (3), respectively.

$$
\begin{gathered}
W \hat{T} P_{i}=\beta_{0}+\beta_{1} \times X_{1}+\cdots+\beta_{n} \times X_{n}+\varepsilon_{i} \\
\overline{W T P}=\frac{\sum_{i=1}^{N} W \hat{T} P_{i}}{N}
\end{gathered}
$$

\subsection{Estimation of the WTP Prices for Houses in the Peripheries of MRT Stations}

After the questionnaire survey was completed, basic statistical tests (correlation analysis, tolerance analysis, and variance inflation factor calculation) were performed to verify whether the factors influencing house prices in the peripheries of stations collected in this study were appropriate. Subsequently, LIMDEP was used to establish Tobit regression models for elevated and underground stations. The factors influencing house prices in the peripheries of MRT stations in the Taipei 
metropolitan area were clarified. Then, the prices that respondents were willing to pay to buy such houses compared with regular houses were estimated.

\section{Questionnaire Design and Survey}

The questionnaire survey in this study was divided into two stages. In the first stage, through the inquiry model of the open-ended method, the initial price basis was determined for use in the official questionnaire in the second stage. For the second-stage questionnaire, the respondents' opinions regarding the factors that influence house prices in the peripheries of stations were collected. Later, the respondents were guided step by step to propose additional prices they would be willing to pay to buy the houses in the peripheries of the MRT stations by using the inquiry model of the open DBDC method designed in this study. The details are provided in the following subsections.

\subsection{First-Stage Questionnaire}

The contents of the first-stage questionnaire first allowed respondents to assess the positive and negative conditions of amenities and environmental qualities in the areas surrounding MRT stations. Subsequently, they were provided with the average price per square meter of the administrative district of the MRT station as well as the average price per square meter of the houses within $500 \mathrm{~m}$ of that MRT station. Then, the respondents were asked how much money they would be willing to pay per square meter to buy a house in the peripheries of the MRT stations based on the average unit price of the houses in that administrative district.

The house prices in the administrative districts where the six MRT stations are located as well as the prices of houses within $500 \mathrm{~m}$ of these stations from October 2016 to October 2018 were obtained from the Real Estate Actual Price Inquiry website of the Ministry of the Interior, Taiwan. A total of 2857 house transaction data items were found for these 2 years in Shilin and Beitou Districts, where the elevated MRT stations (Mingde, Qilian, and Beitou Stations) are located, with an average house price of US\$3847 per square meter. Within $500 \mathrm{~m}$ of these 3 MRT stations, 46 house transaction data items were found, with average house prices per square meter of US $\$ 4854$ (Mingde Station), US\$6026 (Qilian Station), and US\$5750 (Beitou Station). For Wenshan and Xindian Districts, where the underground MRT stations (Wanlong, Dapinglin, and Xindian District Office Stations) are located, 8416 house transaction data items were recorded in the recent 2 years, with an average house price of US $\$ 4506$ per square meter. Within $500 \mathrm{~m}$ of these 3 MRT stations, 84 house transaction data items were recorded, with average house prices per square meter of US\$5201 (Wanlong Station), US $\$ 5566$ (Dapinglin Station), and US\$5002 (Xindian District Office Station). The surrounding areas of the six stations were included in the survey in this study. Thus, the related price information of these six areas differed in the questionnaire. An example of an item of the first-stage questionnaire for Wanlong Station, an underground MRT station, is presented as Box 1.

Box 1. Questions of the first-stage questionnaire.

According to the house prices announced by the government, the average unit price of houses in Wenshan District, Taipei City, from October 2016 to October 2018 was US $\$ 4015$ per square meter. Considering the amenities and environment qualities of the peripheries of the MRT station, how much money per square meter would you be willing to pay additionally on the basis of the average unit price of US\$4015 to buy a house within $500 \mathrm{~m}$ of Wanlong Station?

When questionnaires designed with the CVM are used, individuals who object to the survey may not respond to any questions; some may provide positive responses, but invalid bids (outliers); whereas others may state a value of zero for a good that they actually value (protest zero bids) [67]. The questionnaire used in this study focused on identifying the respondents' WTP additional prices for houses in the peripheries of mass transit stations based on the prices of regular house after they considered the amenities and environmental qualities in these areas. Therefore, if the respondents 
believed that living in the special area provided no benefit, the WTP additional price would be zero, indicating that the respondents were only willing to purchase house products with regular housing prices. Given the characteristics of this study, the responses were acceptable.

The first-stage questionnaire survey was conducted from 6 to 12 November 2018. After invalid samples with omissions or contradictions were omitted, 277 valid questionnaires were retrieved from the surrounding areas of the 6 stations. Subsequently, to avoid respondents' positive but invalid bids and subsequent bias in WTP estimation, we ranked the WTP prices of the six stations from high to low. The highest $10 \%$ of prices for houses in the peripheries of each station were considered outliers and removed. The remaining $90 \%$ of the sample was calculated using quantiles and organized into five price groups for each of the six stations (as shown in Table 2). The five price groups were used as the initial price basis for the second-stage questionnaire. The halved prices of the five groups were used as the basis for price increment or decrement for the second elicitation in the second stage.

Table 2. Willing-to-pay price distribution in the first-stage questionnaire (unit: US $\$ / \mathrm{m}^{2}$ ).

\begin{tabular}{|c|c|c|c|c|}
\hline \multirow[b]{2}{*}{ Group } & \multirow{2}{*}{$\begin{array}{r}\begin{array}{r}\text { Station } \\
\text { Amount }\end{array} \\
\end{array}$} & \multicolumn{3}{|c|}{ Elevated MRT Stations } \\
\hline & & Mingde Station & Qilian Station & Beitou Station \\
\hline & 1 & 100 & 500 & 500 \\
\hline & 2 & 200 & 1000 & 800 \\
\hline & 3 & 400 & 1600 & 1200 \\
\hline & 4 & 700 & 1800 & 1300 \\
\hline & 5 & 1000 & 2200 & 1800 \\
\hline & Station & \multicolumn{3}{|c|}{ Underground MRT Stations } \\
\hline Group & Amount & Wanlong Station & Dapinglin Station & Xindian District Office Station \\
\hline & 1 & 300 & 200 & 200 \\
\hline & 2 & 500 & 250 & 250 \\
\hline & 3 & 600 & 300 & 300 \\
\hline & 4 & 800 & 500 & 400 \\
\hline & 5 & 1000 & 800 & 500 \\
\hline
\end{tabular}

Data source: Prepared by the authors.

\subsection{Second-Stage Questionnaire}

The items in the second-stage questionnaire were rated using a five-point Likert scale. The respondents were asked their opinions on the factors influencing the house prices in the peripheries of an MRT station. Subsequently, according to the five sets of WTP prices obtained from the first-stage questionnaire, each respondent was guided to provide the additional prices they would be willing to pay to purchase a house in the area surrounding the MRT station studied. The collected data were used in the Tobit regression models to confirm the WTP prices of respondents for houses near each MRT station by using the respondents' perceived factors affecting prices of such houses. An example of the item of the second-stage questionnaire for Wanlong Station, an underground MRT station, is presented subsequently.

According to the results of the first-stage survey, five sets of inquiry amounts were confirmed for each area; the amounts were separately included, thus yielding five versions of questionnaire for each MRT station. The second-stage survey was conducted from 28 November to 7 December 2018. In the surrounding area of each station, 200 questionnaires were distributed, totaling 1200 questionnaires for the surrounding areas of all stations. After invalid samples with omissions or contradictions were eliminated, 526 valid questionnaires remained for the peripheries of the elevated MRT stations, whereas 567 valid questionnaires remained for the peripheries of the underground MRT stations, is presented as Box 2. 
Box 2. Questions of the Second-stage questionnaire.

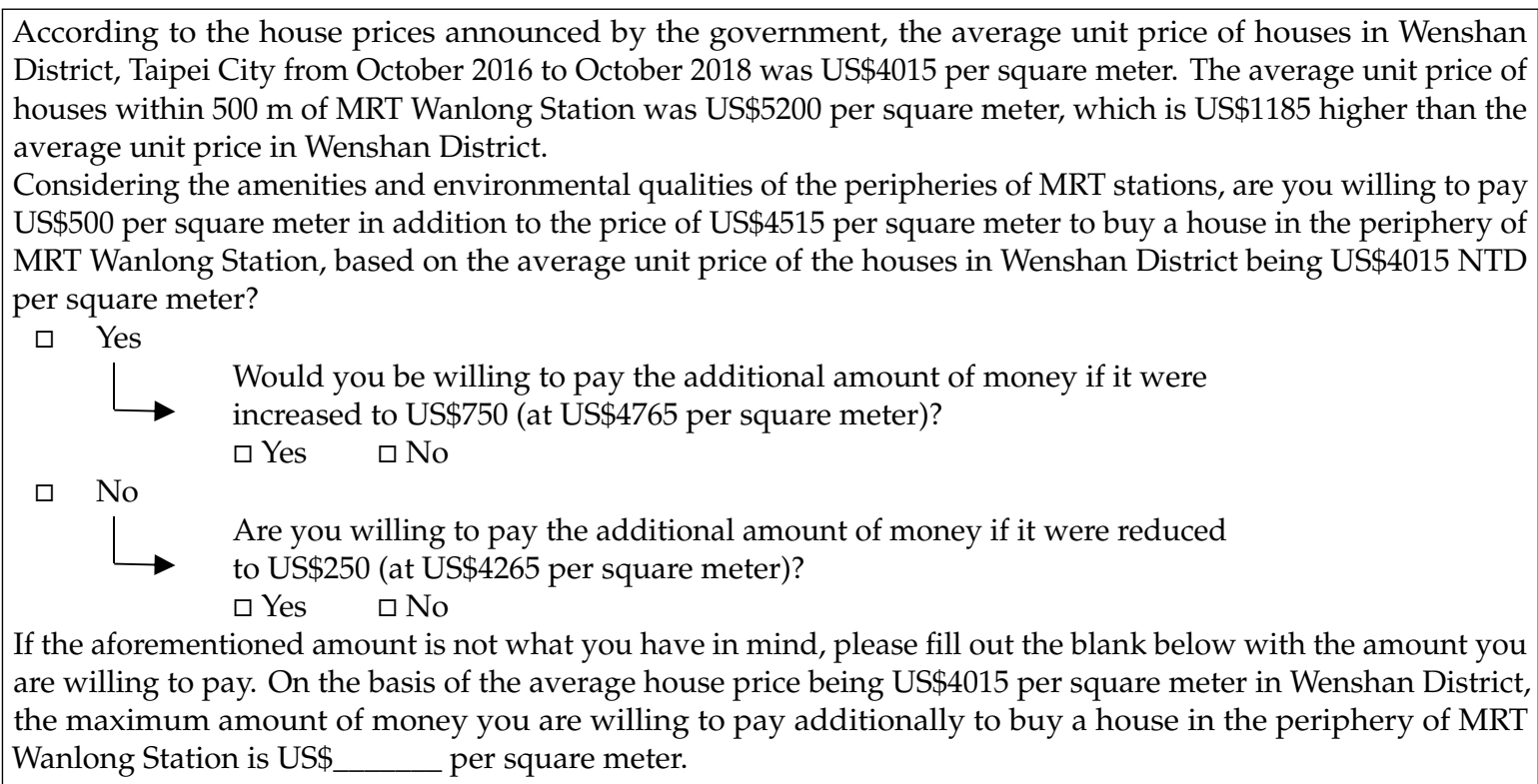

\section{Empirical Results}

\subsection{Basic Statistical Tests}

In this study, basic statistical tests were conducted on the 13 factors influencing house prices in the peripheries of MRT stations obtained from the second-stage questionnaire survey. Thus, it was determined whether these factors were suitable for incorporation in the Tobit regression model. In addition, the factors that needed to be eliminated in model calibration to prevent deviations in the model results were determined.

The tolerance value and variance inflation factors were determined. For the questionnaire data of the peripheries of both the elevated and underground stations, the tolerance values of all 13 influencing factors were larger than 0.1 , and the variance inflation factors for all 13 influential factors were less than 10. This indicated that none of these factors had multicollinearity. The results of the correlation analysis indicated that for the questionnaires in the peripheries of the elevated stations, the $r$ value between "pedestrian walking systems around the stations improve the convenience of the overall walking space (GQ5)" and "traffic congregation influences the serenity of the living environment (BQ5)" was 0.827 , indicating a strong correlation. For the peripheries of the underground stations, the $r$ value between "additional public art installations to the stations improve the esthetics of the living environment (GQ6)" and "traffic congregation influences the air quality of the living environment (BQ2)" was 0.811 , indicating that the two factors exhibited a strong correlation. The results served as a reference for the deletion of influencing factors in the calibration of the Tobit regression model.

\subsection{Calibration Results of the Tobit Regression Model}

Tobit regression models for the peripheries of the elevated and underground MRT stations were established, and the likelihood-ratio indexes $\left(\rho^{2}\right)$ were 0.2257 and 0.2509 , respectively. This indicated that the two models had favorable goodness of fit and significant explanatory power.

As shown in Table 3, the factor "diverse public transportation provides fast and convenient transfer functions (GQ2)" exhibited a significant positive effect in the model of elevated stations; specifically, elevated MRT stations can lead to the congregation of related transportation facilities (e.g., bus stations, public bicycle rental stations, and taxi stops). The higher the recognition levels respondents had for this transportation transfer function, the more they were willing to pay to buy houses in the peripheries of these stations. However, this factor was not significant in the model of underground stations. This may 
be because the MRT routes in the Taipei metropolitan area pass through areas with narrow roads and dense buildings. Consequently, a construction method wherein both the rails and station facilities were set up underground had to be adopted. Only the entrances and mechanical and electrical facilities were established above the ground. Thus, the land areas on the ground are insufficiently large for supportive transportation transfer facilities. For elevated stations, land areas of a certain range must be used for the tracks. In addition, the land on the ground or elevated levels must be used by the stations. Consequently, more space is available for transportation transfer facilities; residents in the peripheries of elevated stations are not limited to using the MRT system alone, and the convenience of using other transportation for residents is high. By contrast, underground MRT stations do not have these functions. The factor "additional open space at the stations improves the recreational functions of the living environment (GQ4)" showed a significant positive effect in the models of both types of stations. This was because both elevated and underground stations, particularly elevated stations, have open spaces around them. These recreational facilities directly create benefits of amenities for people and thus increase their willingness to pay higher house prices. Notably, the factor "mixed land use provides abundant and convenient commercial functions (GQ3)" was not significant in both the elevated and underground station models. These results indicate that the commercial functions of the peripheries of MRT stations in the Taipei metropolitan area are insufficient for respondents to pay an additional price for houses in the areas. This can be attributed to the highly concentrated and mixed land use pattern in Taiwan's urban development, in contrast to that of Western countries. In the Taipei metropolitan area, people's needs for commercial services are satisfied easily and conveniently. Consequently, people do not particularly desire to live in the surrounding areas of stations to obtain superior daily life services.

Table 3. Regression model results for the additional willing-to-pay prices for houses in the peripheries of MRT stations.

\begin{tabular}{ccccc}
\hline \multirow{2}{*}{ Station Type Variable } & \multicolumn{2}{c}{ Elevated MRT Station } & \multicolumn{2}{c}{ Underground MRT Station } \\
\cline { 2 - 5 } & Coefficient & $p$-Value & Coefficient & $p$-Value \\
\hline Constant & 64.1115 & 0.8561 & 307.5472 & 0.4933 \\
GQ1 & -82.4639 & 0.3209 & 81.6459 & 0.1424 \\
GQ2 & $244.1896^{* * *}$ & 0.0044 & 48.4192 & 0.2498 \\
GQ3 & -39.0976 & 0.5336 & -35.2468 & 0.4407 \\
GQ4 & $169.7697^{* *}$ & 0.0103 & $108.6497 * * *$ & 0.0095 \\
GQ5 & 76.2604 & 0.1528 & -26.8994 & 0.4967 \\
GQ6 & -83.8331 & 0.1500 & 56.7177 & 0.2156 \\
BQ1 & -36.7867 & 0.4031 & $-51.9199^{*}$ & 0.0739 \\
BQ2 & 0.4426 & 0.9941 & 0.6542 & 0.1785 \\
BQ3 & 3.6184 & 0.9367 & 48.9747 & 0.1424 \\
BQ4 & $-97.5535^{*}$ & 0.0595 & -32.7417 & 0.4285 \\
BQ5 & -62.6702 & 0.3564 & -48.6202 & 0.2525 \\
BQ6 & -46.5519 & 0.4162 & $-65.2189 *$ & 0.0645 \\
BQ7 & 86.4634 & 0.1110 & $-86.3589 * *$ & 0.0101 \\
USE & -30.7837 & 0.7044 & 67.2104 & 0.2282 \\
AGE & 34.0040 & 0.3640 & -60.6347 & 0.2290 \\
COU & $193.3824^{* *}$ & 0.0168 & $166.7056^{* * *}$ & 0.0041 \\
CT & -95.0298 & 0.1152 & 86.4056 & 0.2011 \\
EDU & 26.5146 & 0.5989 & 127.3080 & 0.1310 \\
INC & $110.7526^{* * *}$ & 0.0009 & $107.7989 * * *$ & 0.0000 \\
$\rho^{2}$ & \multicolumn{2}{c}{0.2257} & & 0.2509 \\
\hline DUyyyyy & & & & \\
\hline
\end{tabular}

Data source: Prepared by the authors. Note: ${ }^{* * *} p<0.01 ;{ }^{* *} p<0.05 ;{ }^{*} p<0.1$.

Regarding negative influential factors, the factor "crowds influence the cleanliness of the living environment (BQ4)" exhibited a significant negative effect only in the elevated station model. This is because elevated stations have larger hinterlands and have corridor space under the elevated rails. 
Consequently, vendors often gather there for business, and relatively busy commercial activities have negative effects on surrounding areas in terms of environmental cleanliness. Regarding the underground station model, the three factors "traffic congregation results in insufficient parking space (BQ1)," "noise and vibrations produced by the MRT system influence the serenity of the living environment (BQ6)," and "buildings and additional facilities of MRT stations influence the landscapes of the living environment (BQ7)" exhibited significant negative influences. These findings indicate that the stronger the perception of these three factors among the respondents, the less willing they are to pay more for houses in the peripheries of underground stations. Such results are clearly related to the structural patterns of underground stations. As mentioned earlier, underground stations require a small land area at ground level. Consequently, parking space is insufficient, which results in inconvenient parking in the peripheries of underground stations. In addition, because of the space problem, transformer boxes and ventilation facilities can be set only next to streets. Thus, the respondents had negative feelings toward the landscapes of underground stations. Generally, the established impression of elevated stations is that the tall stations and tracks affect the visual landscapes of the surrounding areas. However, the empirical results indicated otherwise possibly because in the construction design phase of elevated stations in the Taipei metropolitan area, the fusion of station forms with the surrounding buildings was already valued. Thus, inharmony between station forms and the surrounding environment was avoided. In addition, the stations and corridor space under the tracks increase residents' accessibility to green space and street furniture. Thus, residents do not have negative feelings toward the visual landscapes. In addition, underground stations are mostly in areas with narrow roads and concentrated buildings. Low-frequency noise and vibrations created when MRT trains pass through also caused respondents to doubt the serenity of the living environment.

Regarding personal social economic conditions, family income exhibited a significant positive effect in the models of both station types. This indicates that the higher the family income, the more willing respondents are to pay more for houses in the peripheries of stations. This result is consistent with that of Lund (2006), who conducted investigations in the San Francisco Bay Area, Los Angeles, and San Diego [18]. People who currently lived within $500 \mathrm{~m}$ of an MRT station also exhibited a significant positive effect on the results of both models. This indicates that people currently living in the peripheries of stations (in their own houses or rented housing) are willing to pay more for houses also in the said peripheries. This result can be interpreted as indicating that respondents who currently live in the peripheries of stations still believe that houses in those areas are worth more after experiencing the advantages and disadvantages of living there.

\subsection{WTP Prices for Houses in the Peripheries of MRT Stations}

The Tobit regression model established in this study is shown in Equation (4). $W T P_{i}$ presents the WTP additional prices per square meter for houses in the peripheries of MRT stations; $\beta_{0} \ldots \beta_{20}$ represent the calibration coefficients; $\varepsilon_{i}$ represents the random error term; $G Q_{1} \ldots G Q_{6}$ represent the positive factors influencing house prices in the peripheries of MRT stations. $B Q_{1 \ldots} B Q_{7}$ represent the negative factors influencing house prices in the peripheries of MRT stations. USE, AGE, COU, CT, EDU, INC represent the factors of personal social economic conditions.

$$
\begin{aligned}
\mathrm{WTP}_{i}=\beta_{0}+ & \beta_{1} G Q 1+\beta_{2} G Q 2+\beta_{3} G Q 3+\beta_{4} G Q 4+\beta_{5} G Q 5+\beta_{6} G Q 6+\beta_{7} B Q 1 \\
& +\beta_{8} B Q 2+\beta_{9} B Q 3+\beta_{10} B Q 4+\beta_{11} B Q 5+\beta_{12} B Q 6+\beta_{13} B Q 7 \\
& +\beta_{14} U S E+\beta_{15} A G E+\beta_{17} C O U+\beta_{18} C T+\beta_{19} E D U+\beta_{20} I N C+\varepsilon_{i}
\end{aligned}
$$

According to Equation (4), this study establishes WTP estimation models for elevated and underground stations in Equations (5) and (6) respectively. This can be used to estimate the extra 
price people would be willing to pay to buy the houses in the peripheries of the MRT, compared with regular houses.

$$
\begin{gathered}
W \hat{T} P_{i}=64.1115+244.1896 \times G Q 2+169.7697 \times G Q 4-97.5535 \times B Q 4 \\
+193.3824 \times C O U+110.7526 \times I N C+\varepsilon_{i} \\
W \hat{T} P_{i}=307.5472+108.6497 \times G Q 4-51.9199 \times B Q 1-65.2189 \times B Q 6 \\
-86.3589 \times B Q 7+166.7056 \times C O U+107.7989 \times I N C+\varepsilon_{i}
\end{gathered}
$$

As shown in Table 4, the average market price of the houses in the peripheries of the elevated MRT stations is US $\$ 5543$ per square meter. This is up to US $\$ 1696$ higher than the average market price of houses in the administrative district where the stations are located, with a difference of more than $40 \%$. The estimation results indicated that when the average market price in the entire administrative district was US $\$ 3847$, the respondents were willing to pay an additional US $\$ 304$ per square meter to purchase houses in the peripheries of elevated stations, that is, they were willing to pay up to US\$4151 per square meter. The average market price of the houses in the peripheries of the underground MRT stations is US\$5295 per square meter. The difference between this price and the average market price of houses in the districts where the stations are located is US\$941, which is $21.6 \%$ higher. This study estimated that after considering the advantages and disadvantages of the amenities and environment qualities of the peripheries of stations, the respondents were willing to pay an additional US\$257 per square meter for houses, with the average house price of all administrative districts as their basis for judgment. Specifically, the respondents were willing to purchase houses in the peripheries of underground MRT stations at a price of US $\$ 4611$ per square meter. Accordingly, the TOD-based living fields caused the housing submarket in the peripheries of mass transportation stations to develop differently from the housing submarket in ordinary regions, affecting individuals' willingness to pay for housing. Specifically, the empirical results of this study revealed that, in the Taipei metropolitan area, the establishment of mass transit stations changed the amenities and environmental qualities of the adjacent peripheries. After consideration of the advantages and disadvantages of living in such regions, individuals were more willing to pay higher prices in such housing submarkets than in ordinary ones.

Table 4. Prices that the respondents were willing to pay and the market prices of houses in the peripheries of the MRT stations.

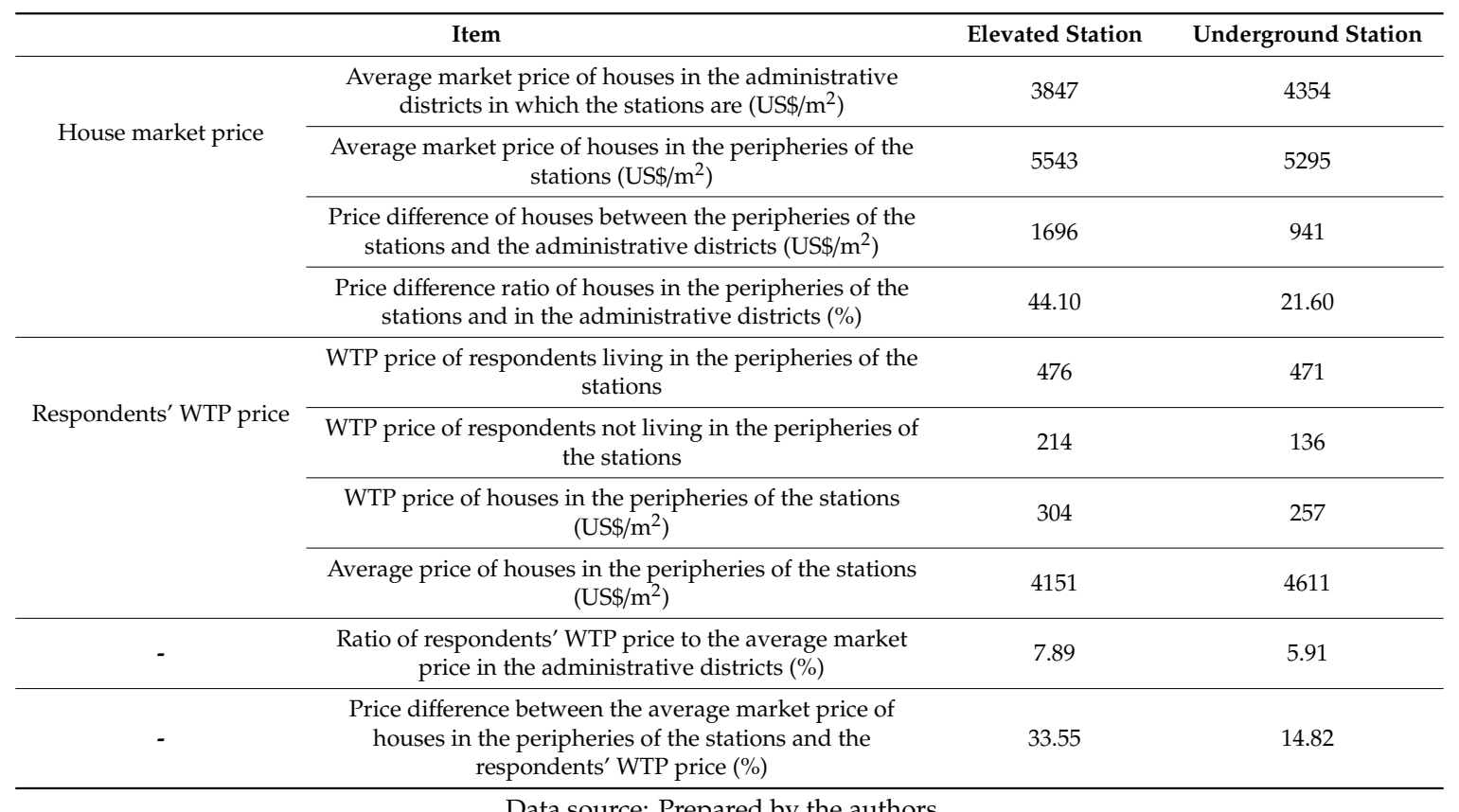

Data source: Prepared by the authors. 
In addition, perceptions regarding the advantages and disadvantages of the amenities and environmental qualities derived from the surrounding areas varied among respondents for different station types. Consequently, the additional WTP prices also differed when respondents made purchase decisions for houses in these areas. For houses near elevated stations, the respondents were willing to pay approximately an additional $7.89 \%$ above the average market price of houses in the entire district per square meter. For those near underground stations, the respondents were willing to pay approximately an additional $5.9 \%$ above the average market price of houses in the entire district per square meter. The results of the Tobit regression models were further used to explain the reasons for these findings. In the constructed models, transportation transfer convenience as well as the open and recreational space near the elevated stations generated positive effects, thereby increasing the respondents' willingness to pay more. Only the factor of unfavorable cleanliness of the environment surrounding the stations negatively influenced the WTP prices. Underground stations have more factors that negatively influence WTP prices, including traffic congregation causing insufficient parking space, noise and vibrations generated by the MRT system influencing the amenity of the living environment, and buildings and additional facilities of the MRT station influencing the landscapes of the living environment. Consequently, the houses in the peripheries of elevated stations were slightly more attractive to respondents compared with those in the peripheries of underground stations. To conclude, the respondents were willing to pay prices higher than those of average houses to own houses in the peripheries of the MRT stations to enjoy more diverse transportation services, open space, and recreational facilities. Therefore, the first study hypothesis was supported.

The differences in the current residential locations of respondents were further observed. For both elevated and underground stations, the respondents currently living in the peripheries of stations were willing to pay more than those who did not live in such areas. In addition, the price differences were up to 1.22 and 2.45 times higher for houses near elevated and underground stations, respectively. Compared with respondents who did not live in the peripheries of stations, who offered more conservative prices, the respondents already living in those areas were willing to pay more for houses in those areas. This was because they were already dependent on the additional advantages of the surrounding areas of stations in their daily lives.

However, in the peripheries of both the elevated and underground stations, the current house market prices were higher than those that the respondents were willing to pay. In the peripheries of the elevated stations, the market prices of houses were $33.55 \%$ higher than the house prices respondents were willing to pay. For houses in the peripheries of underground stations, the market prices were $14.82 \%$ higher than the prices respondents were willing to pay. Since the MRT started operation in the Taipei metropolitan area in 1996, the expansion of MRT routes has been ongoing. When land development and urban renewal are conducted in the peripheries of stations, the marketing of house products mostly emphasizes the advantages derived from being near MRT stations. Thus, the particularity of houses in the peripheries of MRT stations is gradually being established. Under such market trends and the registration system for the actual selling prices of real estate effective since 2012, sellers must report the actual transaction prices of house products to competent authorities. This credible price information system has an anchoring effect on the market. Although prospective house buyers have their suitable WTP price for a house product, they must accept existent transaction prices on the market to obtain market-oriented special houses. Consequently, the market prices for this special housing type increase gradually, even to a level beyond the value that home buyers assume. This result verified the second hypothesis.

\section{Conclusions}

Growth management refers to the introduction of urban growth activities to suitable areas at the appropriate time. Moreover, public transit is used to connect land use activities and construct urban residential living environments with a concentrated mixed use of residential and commercial zoning. Thus, the urban sprawl of a metropolis is slowed. In addition, the efficiency of land and 
environmental use is increased, thus increasing construction investment. Based on this idea of sustainable development, local governments can use the TOD strategy to reconstruct land use patterns in the peripheries of public transit stations (including increasing the efficiency of the mixed use of residence and commerce, increasing building height, and renewing pedestrian walkways). Thus, people's dependence on vehicles for personal transport is expected to decrease, and the problems of worsening traffic congestion, air pollution, and noise pollution will be subsequently reduced. The sustainable planning of this type of metropolis also allows houses in the peripheries of public transit stations to become a special product in the housing market. In this study, the Taipei metropolitan area was used as an example, and a questionnaire was designed using the open DBDC model based on the CVM. After the respondents considered the advantages and disadvantages of the amenities and environmental qualities of the peripheries of MRT stations, the additional prices they would be willing to pay to purchase houses in those areas compared with those for regular houses were estimated. Thus, the present research clarified whether the living environment shaped by the land use patterns that fit sustainable development are popular. Additionally, the results reflect the actual housing prices and the presence of price gouging. The findings are described in three aspects as follows:

First, CVM is generally used to estimate the value of nonmarket goods. However, the method can also be used for market goods for which prices are currently unavailable. Studies regarding real estate prices have mostly used the CVM to explore the effect of environmental pollution on housing prices [50-54,56-61,68]. This study applied CVM to explore the WTP of houses in the peripheries of mass transit stations. It is different from other studies that focus on the housing market price level changes before and after the operation of mass transit stations, the scope of effect, and their causes [15-31]. This study is the first to use the CVM to estimate the house prices of the peripheries of public transit stations. The respondents were allowed to consider their positive and negative feelings toward amenities and environmental qualities if they lived in these areas and determine the house prices they would be willing to pay. An empirical analysis was used to demonstrate the differences between the market prices of houses in the peripheries of MRT stations and the prices that the respondents were willing to pay. This organized empirical design framework may serve as a reference for relevant future studies.

Second, the empirical results suggested that the recreational functions of peripheries are improved by the additional open space near both elevated and underground MRT stations. Thus, people are willing to pay more for houses in these areas compared with regular houses. Next, the introduction of TOD strategies in urban planning entails using mixed land use to improve the commercial functions and convenience of residents' daily lives. Thus, the attractiveness of the areas surrounding public transit stations is increased. This is the main reason for the higher housing prices in the peripheries of public transit stations in European and North American countries. However, current land use patterns in urban areas in Taiwan are already concentrated with a mix of residence and commerce. Therefore, people can satisfy their needs for commercial services easily and conveniently with the shops near their houses without the demand of living in the peripheries of public transit stations to obtain superior commercial services. Therefore, abundant commercial function is not why people are willing to pay more to purchase houses in these areas. This finding is different from the development characteristics of urban areas in European and North American countries. In the Taipei metropolitan area, both elevated and underground stations provide open space that can improve the leisure functions of the peripheries, thus increasing people's WTP for house products in the peripheries of the stations than regular house products. Apart from the positive factors that affect housing prices in the peripheries of mass transit stations in the Taipei metropolitan area, factors such as insufficient parking space and the compromised tranquility of the residential environment due to noise and vibrations resulting from the MRT system negatively affect people's decisions to purchase houses in the peripheries of MRT stations. Because elevated stations feature greater hinterland areas and corridor spaces beneath the elevated railways, the relatively more active commercial activities and intense crowds negatively affect the environment; this effect is reflected in people's house purchase decisions. The negative factors 
affecting the housing prices of the peripheries of the stations are similar to those in European and North American metropolitan areas [14-16].

Third, respondents were willing to pay more for houses in the peripheries of both elevated and underground stations after considering the advantages and disadvantages of living in these areas. However, they perceived the advantages and disadvantages of living in the surrounding areas of different types of MRT stations differently, leading to different additional prices that they were willing to pay for houses near those stations. The additional amount people were willing to pay per square meter was approximately $7.89 \%$ and $5.9 \%$ more than the average market price of houses in the entire administrative district for houses in areas surrounding elevated stations and underground stations, respectively. In addition, in daily life, people already living in the peripheries of stations were dependent on the additional advantages of such areas. Thus, their WTP price was higher than that of people who did not live in such areas. Furthermore, this study verified that the market prices of the houses in the peripheries of MRT stations were higher than the prices people were willing to pay after considering the advantages and disadvantages of amenities and environmental qualities. Specifically, the market price of houses in areas surrounding elevated stations was $33.55 \%$ higher, and that of houses in areas surrounding underground stations was $14.82 \%$ higher, indicating that the market prices of this type of house product already surpass the values they should have.

To conclude, people are willing to pay more to purchase this type of house product in the Taipei metropolitan area compared with regular houses. This indicates that the TOD-based living fields are popular to some degree. However, the factors affecting amenities and environmental qualities of the areas surrounding transit stations differ between Taiwan and European and North American countries. Subsequent studies can use the analytical framework established in this study to further discuss the situations of Asian metropolises such as Shanghai, Hong Kong, Seoul, and Tokyo. The results of the study systematically present the characteristic differences in urban development between Asian and Western countries. Thus, current planning ideas and strategic systems created according to the characteristics of urban areas in Western countries can be further examined to clarify the required adjustments for the implementation of such ideas and strategies in Asian cities. In addition, similar to Western countries, the prices of houses in the peripheries of MRT stations are higher than those of regular houses. For middle-class and young populations, buying houses in such areas is difficult. However, according to the social development characteristics of the Taipei metropolitan area, Taipei residents comprise the major population that commutes using the MRT. Individuals living a certain distance from MRT stations continue to use private vehicles for their commutes or other transfer transportation. Thus, to increase the benefits of TOD and implement growth management in the Taipei metropolitan area, the structural predicament caused by current market mechanisms should be gradually improved by adjusting related policies and establishing complementary measures. Regarding housing policy adjustment, the supply of affordable housing and social housing in the peripheries of MRT stations should be increased with a floor area incentive mechanism. Thus, opportunities for middle-class and young populations to buy or rent houses in the areas surrounding stations can be increased. In other words, new buildings must be composed of certain ratios of affordable or social housing to obtain additional floor area. Moreover, regarding the adjustment of land use projects, transit-oriented corridors should be introduced in TOD for urban renewal projects or large-scale block remodeling should be adapted in the peripheries of MRT stations in the future. The planning of space corridors should be combined with the development of areas surrounding multiple MRT stations. A basis for pedestrian-oriented space should be created through overall network connections, walking corridor configuration, and reinforcement of commercial facilities along streets.

Finally, by using data such as the house price-to-income ratio, future studies can identify whether housing price levels in the peripheries of the stations exert an excessive load on prospective house buyers. Furthermore, questionnaires can be used to obtain detailed demographic data of prospective house buyers, such as household compositions and the area of houses to be purchased. In this way, the variance on the affordability of houses for buyers with different socioeconomic backgrounds will be 
analyzed. In addition, in the entire MRT network, differences in station scale, relative location, and functional orientation generate various types of stations. The market characteristics of houses in the peripheries of stations also differ, thereby forming different housing submarkets and engendering different levels of attractiveness to prospective house buyers. Future studies should set different types of stations as targets to compare the characteristics of prospective house buyers' house purchase decisions and WTP prices in different housing submarkets.

Funding: This research received no external funding.

Conflicts of Interest: The authors declare no conflict of interest.

\section{References}

1. Ewing, R.H. Characteristics, Causes, and Effects of sprawl: A Literature Review. Environ. Urban Issues 1994, $21,1-15$.

2. Breheny, M. Urban Compaction: Feasible and Acceptable? Cities 1997, 14, 209-217. [CrossRef]

3. Brueckner, J.K. Urban Sprawl: Diagnosis and Remedies. Int. Reg. Sci. Rev. 2000, 23, 160-171. [CrossRef]

4. Freeman, L. The Effects of Sprawl on Neighborhood Social Ties. J. Am. Plan. Assoc. 2001, 67, 69-77. [CrossRef]

5. Hess, G.R.; Daley, S.S.; Derrison, B.K.; Lubkin, S.R.; McGuinn, R.P.; Morin, V.Z.; Potter, K.M.; Savage, R.E.; Shelton, W.G.; Snow, C.M.; et al. Just What is Sprawl, Anyway? Carol. Plan. 2001, 26, 11-26.

6. Weiler, S. Pioneers of Rural Sprawl in the Rocky Mountain West. Rev. Reg. Stud. 2003, 33, 264-283.

7. Hsu, K.C.; Lai, T.Y.; Li, C.N. Why the urban pattern toward sprawling development? Proc. Inst. Civ. Eng. Urban Des. Plan. 2016, 169, 200-208. [CrossRef]

8. Gordon, P.; Richardson, H.W. Are Compact Cities a Desirable Planning Goal? J. Am. Plan. Assoc. 1997, 63, 95-106. [CrossRef]

9. Burchell, R.W.; Shad, N.A.; Listokin, D.; Phillips, H.; Downs, A.; Seskin, S.; Davis, J.S.; Moore, T.; Helton, D.; Gall, M. The Cost of Sprawl-Revisited; National Academy Press: Washington, DC, USA, 1998.

10. Burton, E. The Compact City: Just or Just Compact? A Preliminary Analysis. Urban Stud. 2000, 37, 1969-2001. [CrossRef]

11. Johnson, M.P. Environment Impacts of Urban Sprawl: A Survey of the Literature and Proposed Research Agenda. Environ. Plan. A 2001, 33, 717-735. [CrossRef]

12. Bengston, D.N.; Potts, R.S.; Fan, D.P.; Goetz, E.G. An analysis of the public discourse about urban sprawl in the United States: Monitoring concern about a major threat to forests. For.t Policy Econ. 2005, 7, 745-756. [CrossRef]

13. Chapin, T.S. From Growth Controls, to Comprehensive Planning, to Smart Growth: Planning's Emerging Fourth Wave. J. Am. Plan. Assoc. 2012, 78, 5-15. [CrossRef]

14. Mulley, C.; Ma, L.; Clifton, G.; Yen, B.; Burke, M. Residential property value impacts of proximity to transport infrastructure: An investigation of bus rapid transit and heavy rail networks in Brisbane, Australia. J. Transp. Geogr. 2016, 54, 41-52. [CrossRef]

15. Diaz, R.B.; Mclean, V.A. Impacts of rail transit on property values. In Proceedings of the American Public Transit Association Rapid Transit Conference, Toronto, OH, USA, 22-27 May 1999; pp. 1-8.

16. Debrezion, G.; Eric, P.; Piet, R. The Impact of Railway Stations on Residential and Commercial Property Value: A Meta-analysis. J. Real Estate Financ. 2007, 35, 161-180. [CrossRef]

17. Kilpatrick, J.A.; Throupe, R.L.; Carruthers, J.I.; Krause, A. The Impact of Transit Corridors on Residential Property Values. J. Real Estate Res. 2007, 29, 303-320.

18. Lund, H. Reasons for Living in a Transit-Oriented Development, and Associated Transit Use. J. Am. Plan. Assoc. 2006, 72, 357-366. [CrossRef]

19. Bae, C.H.C.; Jun, M.J.; Park, H. The impact of Seoul's subway Line 5 on residential property values. Transp. Pol. 2003, 10, 85-94. [CrossRef]

20. Cervero, R.; Duncan, M. Transit's added value: At what point does locating near transit raise real estate values? Urban Land. 2002, 61, 77-84.

21. Benjamin, J.D.; Sirmans, G.S. Mass transportation, apartment rent and property values. J. Real Estate Res. $1996,12,1-8$. 
22. Workman, S.L.; Brod, D. Measuring the Neighborhood Benefits of Rail Transit Accessibility. Transp. Res. Rec. 1997, 1576, 147-153. [CrossRef]

23. Dueker, K.; Bianco, M.J. Light-Rail-Transit Impacts in Portland: The First Ten Years. Transp. Res. Rec. 1999, 1685, 171-180. [CrossRef]

24. Mulley, C.; Tsai, C.H. when and how much does new transport infrastructure add to property values? Evidence from the bus rapid transit system in Sydney, Australia. Transp. Pol. 2016, 51, 15-23. [CrossRef]

25. Deng, T.; Ma, M.; Nelson, J.D. Measuring the impacts of Bus Rapid Transit on residential property values: The Beijing case. Res. Transp. Econ. 2016, 60, 54-61. [CrossRef]

26. Liou, F.M.; Yang, S.Y.; Chen, B.; Hsieh, W.P. The effects of mass rapid transit station on the house prices in Taipei: The hierarchical linear model of individual growth. J. Pac. Rim Psychol. 2016, 22, 1-14. [CrossRef]

27. Shyr, O.; Andersson, D.E.; Wang, J.; Huang, T.; Liu, O. Where Do Home Buyers Pay Most for Relative Transit Accessibility? Hong Kong, Taipei and Kaohsiung Compared. Urban Stud. 2013, 50, 2553-2568. [CrossRef]

28. Chiang, Y.H. The Reexamination of the Impact of Mass Rapid Transportation on Residential Housing in Metropolitan Taipei. In Proceedings of the European Real Estate Society 20th Annual Conference, Vienna, Austria, 3-6 July 2013.

29. Peng, C.W.; Yang, C.H.; Yang, S.Y. The Impacts of Subways on Metropolitan Housing Prices in Different Locations-After the Opening of the Taipei Subway System. Transp. Plan. J. 2009, 28, 275-296.

30. Hsu, K.C. Effect of Distinct Land Use Patterns on Quality of Life in Urban Settings. J. Urban Plan. D-ASCE 2019, 145, 1-17. [CrossRef]

31. Mohammed, I.; Alshuwaikhat, H.M.; Adenle, Y.A. An Approach to Assess the Effectiveness of Smart Growth in Achieving Sustainable Development. Sustainability 2016, 8, 397. [CrossRef]

32. Boyle, R.; Mohamed, R. State growth management, smart growth and urban containment: A review of the US and a study of the heartland. J. Environ. Plan. Manag. 2007, 50, 677-697. [CrossRef]

33. O'Toole, R. A Portlander's View of Smart Growth. Rev. Austrian Econ. 2004, 17, 203-212. [CrossRef]

34. Chin, T.L.; Chau, K.W.; Ng, F.F. The impact of the Asian financial crisis on the pricing of condominiums in Malaysia. J. Real Estate Lit. 2004, 12, 33-49.

35. Hui, E.C.M.; Chau, C.K.; Pun, L.; Law, M.Y. Measuring the Neighboring and Environmental Effects on Residential Property Value: Using Spatial Weighting Matrix. Build. Environ. 2006, 42, 2333-2343. [CrossRef]

36. Belzer, D.; Autler, G. Countering sprawl with transit-oriented development. Issues Sci. Technol. 2002, 19, 51-58.

37. Geleto, A.K. Contingent valuation technique: A review of literature. ISABB J. Health Environ. Sci. 2011, 1, 8-16.

38. Bishop, R.C.; Heberlien, T.A. Measuring Values of Extra Market Goods: Are Indirect Measures Biased? Am. J. Agric. Econ. 1979, 61, 926-930. [CrossRef]

39. Bowker, J.M.; Stoll, J.R. Use of Dichotomous Choice Nonmarket Methods to Value to Whooping Crane Resource. Am. J. Agric. Econ. 1988, 70, 372-881. [CrossRef]

40. Smith, V.K. A Bound for Option Value. Land Econ. 1984, 60, 292-296. [CrossRef]

41. Hansen, T.B. The Willingness-to-Pay for the Royal Theatre in Copenhagen as a Public Good. J. Cult. Econ. 1997, 21, 1-28. [CrossRef]

42. Cummings, R.G.; Taylor, L.O. Unbiased Value Estimates for Environmental Goods: A Cheap Talk Design for the Contingent Valuation Method. Am. Econ. Rev. 1999, 89, 649-665. [CrossRef]

43. Venkatachalam, L. The contingent valuation method: A review. Environ. Impact Assess. Rev. 2004, $24,89-124$. [CrossRef]

44. Desvousges, W.; Mathews, K.; Train, K. Adequate responsiveness to scope in contingent valuation. Ecol. Econ. 2012, 84, 121-128. [CrossRef]

45. Hausman, J. Contingent Valuation: From Dubious to Hopeless. J. Econ. Perspect. 2012, 26, 43-56. [CrossRef]

46. Mitchell, R.C.; Carson, R.T. Using Surveys to Value Public Goods; The Contingent Valuation Method; Resources for the Future: Washington, DC, USA, 1989.

47. Hutchinson, W.G.; Chilton, S.M.; Davis, J. Measuring Non-use Value of Environmental Goods Using the Contingent Valuation Method: Problems of Information and cognition and the application of cognitive Questionnaire Design Methods. J. Agric. Econ. 1995, 46, 97-112. [CrossRef]

48. List, J.A. Do Explicit Warnings Eliminate the Hypothetical Bias in Elicitation Procedures? Evidence from Field Auctions for Sports cards. Am. Econ. Rev. 2001, 91, 1498-1507. [CrossRef] 
49. Fransico, J.P. Are the Rich Willing to Pay for Beautiful Cities?: Income Effects on the Willingness to Pay for Aesthetic Improvements. Australas J. Reg. Stud. 2010, 16, 233-252.

50. Wattage, P. A Targeted Literature Review-Contingent Valuation Method; University of Portsmouth Press: Portsmouth, UK, 2001.

51. Mattia, S.; Oppio, A.; Pandolfi, A. Testing the use of Contingent Valuation Method in Real Estate Market: First results of an experiment in the city of Milan. Aestimum 2013, 721-734.

52. Roddewig, R.J.; Frey, J.D. Testing the Reliability of Contingent Valuation in the Real Estate Marketplace. Apprais. J. 2006, 74, 267-280.

53. Mundy, B.; McLean, D. Using the contingent value approach for natural resource and environmental damage applications. Apprais. J. 1998, 66, 290-297.

54. Simons, R.A.; Throupe, R. An Exploratory Review of the Effects of Toxic Mold on Real Estate Values. Apprais. J. 2005, 73, 156-166.

55. Simons, R.A.; Geideman, W.K. Determining Market Perceptions on Contamination of Residential Property Buyers Using Contingent Valuation Surveys. J. Real Estate Res. 2005, 27, 193-220.

56. Lipscomb, C.A.; Kummerow, M.; Spiess, W.; Kilpatrick, S.; Kilpatrick, J.A. Contingent Valuation and Real Estate Damage Estimation. J. Real Estate Lit. 2011, 19, 283-305.

57. Kiel, K.A.; McClain, K.T. House Prices during Siting Decision Stages: The Case of an Incinerator from Rumor through Operation. J. Environ. Econ. Manag. 1995, 28, 241-255. [CrossRef]

58. Chattopadhyay, S. Estimating the Demand for Air Quality: New Evidence Based on the Chicago Housing Market. Land Econ. 1999, 75, 22-38. [CrossRef]

59. Beron, K.; Murdoch, J.; Thayer, M. The Benefits of Visibility Improvement: New Evidence from the Los Angeles Metropolitan Area. J. Real Estate Financ. Econ. 2001, 22, 319-337. [CrossRef]

60. Brasington, D.M.; Hite, D. Demand for Environmental Quality: A Spatial Hedonic Analysis. Reg. Sci. Urban Econ. 2005, 35, 57-82. [CrossRef]

61. Jim, C.Y.; Chen, W.Y. Impacts of urban environment elements on residential housing prices in Guangzhou China. Landsc. Urban Plan. 2006, 78, 42-434. [CrossRef]

62. Tan, T.H. Neighborhood preferences of house buyers: The case of Klang Valley, Malaysia. Int. J. Hous. Mark. Anal. 2011, 4, 58-69.

63. Heinzen, R.R.; Bridges, J.F.P. Comparison of four contingent valuation methods to estimate the economic value of a pneumococcal vaccine in Bangladesh. Int. J. Technol. Assess. Health Care 2008, 24, 481-487. [CrossRef]

64. Fonta, W.W.; Ichoku, H.E.; Ogujiuba, K.K. Estimating willingness to pay with the stochastic payment card design: Further evidence from rural Cameroon. Environ. Dev. Sustain. 2010, 12, 179-193. [CrossRef]

65. Hanemann, M.; Loomis, J. Statistical efficiency of double-bounded dichotomous choice contingent valuation. Am. J. Agric. Econ. 1991, 73, 1255-1263. [CrossRef]

66. Lusk, J.L.; Hudson, D. Willingness-to-pay estimates and their relevance to agribusiness decision-making. Rev. Agric. Econ. 2004, 26, 152-169. [CrossRef]

67. Halstead, J.H.; Luloff, A.E.; Stevens, T.H. Protest Bidders in Contingent Valuation. Northeast J. Agric. Econ. 1992, 21, 160-169. [CrossRef]

68. Chalmers, J.A.; Roehr, S. Issues in the Valuation of Contaminated Property. Apprais. J. 1993, 7, $28-41$.

Publisher's Note: MDPI stays neutral with regard to jurisdictional claims in published maps and institutional affiliations.

(C) 2020 by the author. Licensee MDPI, Basel, Switzerland. This article is an open access article distributed under the terms and conditions of the Creative Commons Attribution (CC BY) license (http://creativecommons.org/licenses/by/4.0/). 